\title{
Rationality, Tort Reform and Contingent Valuation: A Classroom Experiment in Starting Point Bias
}

\author{
Victor A. Matheson
}

June 2005

\section{COLLEGE OF THE HOLY CROSS, DEPARTMENT OF ECONOMICS \\ FACULTY RESEARCH SERIES, WORKING PAPER NO. 05-09*}

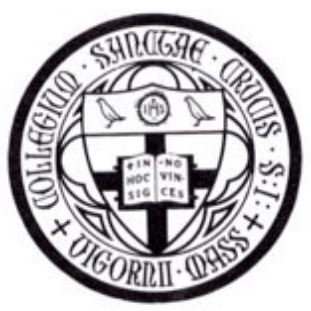

Department of Economics

College of the Holy Cross

Box 45A

Worcester, Massachusetts 01610

(508) 793-3362 (phone)

(508) 793-3710 (fax)

http://www.holycross.edu/departments/economics/website

*All papers in the Holy Cross Working Paper Series should be considered draft versions subject to future revision. Comments and suggestions are welcome. 


\title{
Rationality, Tort Reform and Contingent Valuation: A Classroom Experiment in Starting Point Bias
}

\author{
Victor A. Matheson ${ }^{\dagger}$ \\ College of the Holy Cross
}

June 2005

\begin{abstract}
This simple classroom experiment demonstrates the existence of starting point bias. Asked to place a dollar value on a non-market good such as the loss of a limb or the destruction of a wetland, students place a much smaller value on the loss if a small value is first suggested by the questioner while placing a significantly higher value on the loss when a large value is originally suggested. This experiment can be used in theory classes to demonstrate the limits of individual rationality or in applied classes in law or environmental economics in relation to tort reform or contingent valuation.
\end{abstract}

JEL Classification Codes: A2 - Economics Education and Teaching of Economics; C42 Survey Methods; C91 - Laboratory, Individual Behavior; K41 - Litigation Process; Q51 Valuation of Environmental Effects

Keywords: starting point bias, contingent valuation, classroom experiments, experimental economics

${ }^{\dagger}$ Victor A. Matheson, Department of Economics, Box 157A, College of the Holy Cross, Worcester, MA 01610-2395, 508-793-2649 (phone), 508-793-3710 (fax), vmatheso@holycross.edu 


\section{Rationality, Tort Reform and Contingent Valuation:}

\section{A Classroom Experiment in Starting Point Bias}

\section{INTRODUCTION}

In this classroom experiment, the ability of people to place reasonable dollar values on things such as health, the environment, and human life is tested. The science of economics depends critically on the assumption that people are able to routinely and rationally place specific values non-market goods. Government health and safety regulations are deemed acceptable based upon their cost per life saved, environmental amenities are often valued through the use of survey data (known as contingent valuation), and the tort system is based upon the idea that juries can rationally determine awards that will properly compensate victims for economic damages. Unfortunately, people are not often asked to make such value determinations, and therefore it is reasonable to question the ability of people to make such estimates.

The purpose of this paper is to explain a simple classroom experiment that can be used by teachers of economics or law that can be used to demonstrate how easily people can be misled when asked to estimate the dollar value in a quality of life case. The experiment can be easily altered for use in an environmental and natural resource economics class or any other course in which contingent evaluation is studied. The next section presents the methodology of the experiment. This is followed by one set of results from this experiment. The paper closes with conclusions and suggestions for further research. 


\section{METHODOLOGY}

Students are given a hypothetical situation where they are asked to place a dollar value on some non-market good. In the actual case presented in the "Results" section, all students were told, "Suppose you have been asked to serve on a jury on a matter dealing with personal injury. In the case before you, a 50-year old construction worker was injured on the job due to the negligence of his employer. As a result, this man had his right leg amputated at the knee. Due to this disability, he cannot return to the construction trade and has few other skills with which he could pursue alternative employment. The negligence of the employer has been firmly established and health insurance covered all of the related medical expenses. Therefore, your job is to determine how to compensate this worker for the loss of his livelihood and the reduction in his quality of life.”

One group of students was first asked whether the worker deserved to be compensated more or less than $\$ 10,000$ and then asked how much more or less. Another group of students was first asked whether the worker deserved to be compensated more or less than $\$ 10,000,000$ and then asked how much more or less. In the results presented in the following section, a third group of students was simply asked how much the worker deserved to be compensated without any initial suggestion as to an appropriate amount. This third group was used as a control group for more detailed research but need not be included in a simple classroom experiment.

It is crucial that the students only be exposed to one of the two (or three) monetary suggestions. This can be done either by handing out survey forms that randomly have some students given the $\$ 10,000$ figure and others given the $\$ 10,000,000$ figure or by having half of the students physically leave the classroom while the instructor asks the students to write down a 
number after being orally asked either more or less than $\$ 10,000$ and then having the other half of the students leave the classroom while the second group is given the $\$ 10,000,000$ suggestion. It is, of course, imperative that students not communicate with one another while forming their valuations. In either case, this part of the experiment can be completed in less than 5 minutes.

Tabulation of the student responses can either be done on the spot or outside the classroom by the instructor with results presented in a subsequent class. The experiment has a greater impact on the students if feedback is provided immediately, and a computerized classroom with a spreadsheet or statistical package will greatly speed the process.

\section{RESULTS}

One hundred and sixty-nine undergraduate students comprising three sections of principles of economics and two sections of intermediate microeconomics at a private liberal arts college were posed the aforementioned scenario using survey forms. The questionnaire also included demographic data including gender, year in school, number of economics classes taken, hometown, and political leanings. Copies of these survey forms are available from the author upon request. Again, in this experiment the class was divided randomly into thirds to provide a control group which was not subjected to a starting point bias. In other classroom settings it will be quicker and easier to have only two groups, and this will also maximize the chances of getting the desired results even with small class sizes.

Other scenarios can be posed as long as the basic idea of suggesting different values to different groups is maintained. Through past trials, this particular scenario has been calibrated so that a typical unbiased response will lie in-between the two suggested starting points which 
serves to maximize the observed differences. Table 1 shows the mean and median responses of the three groups along with measures of spread.

The 9 to 1 difference in the mean compensation awarded by those who were initially asked "more or less than $\$ 10,000,000$ " compared to those initially asked "more or less than $\$ 10,000 "$ is striking, and a hypothesis that the two means are equal can be rejected at the $99.9 \%$ significance level. Furthermore, even in the individual classes, some of which had as few as 6 students in each group, in no case was the ratio between the mean response in the two groups subject to a starting point bias less than 2.5 to 1 . Furthermore, in each individual class, even the minimum reported valuation among members of the $\$ 10,000,000$ group matched or exceeded the valuations of between 71 and 89 percent of the members in the $\$ 10,000$ group. This suggests that an instructor is safe to perform this test even in small classes and will still get meaningful results.

Demographic differences appear to have no major effects on valuation. Male students and those identifying themselves as having strong Democratic Party leanings tended to give slightly higher awards (in the neighborhood of a 10 percent premium), than their counterparts, but these differences are dwarfed by the starting point bias. The inclusion of additional questions into the classroom experiment is likely to significantly increase the cost of the project in terms of time and effort without yielding interesting results.

Finally, students with a more extensive economics background did no better (in terms of a narrower spread between the three groups and a lower overall standard deviation) than those students with little or no prior economics experience. Therefore, an instructor can feel confident that interesting results will be achieved regardless of the class level. 


\section{CONCLUSION}

In many cases, people’s estimates of value for non-market goods can be manipulated through the simplest of techniques. While this fact may be well known in theory to many in the field of economics, these economists may not know how easy it is to demonstrate this phenomenon in practice through a quick and easy classroom experiment. Such a demonstration is useful in intermediate microeconomic theory classes when the concept of individual rationality is discussed. This experiment is also useful in field classes in law and economics or public policy in debating the merits of tort reform or caps on jury awards. In addition, the experiment is useful for courses in the field of environmental and natural resource economics, cost benefit analysis, or any other course where contingent valuation, and the limits thereof, is discussed.

\section{ACKNOWLEDGMENTS}

The author would like to thank Mandar Oak, Matthew Kotchen and the students in the Department of Economics at Williams College for graciously using their class time in performing this experiment.

\section{APPENDICES}

This electronic document includes the handouts given in class to the students as well as the results summary that they were given following the tabulation of the data. 
TABLE 1: Results of Starting Point Bias Experiment

\begin{tabular}{lccc}
\hline & $\$ \mathbf{1 0 , 0 0 0}$ suggested & $\mathbf{\$ 1 0 , 0 0 0 , 0 0 0}$ suggested & No suggestion made \\
\hline Mean & $\$ 803,536$ & $\$ 7,206,040$ & $\$ 2,239,036$ \\
Median & $\$ 375,000$ & $\$ 4,000,000$ & $\$ 1,000,000$ \\
Minimum & $\$ 8,000$ & $\$ 500,000$ & $\$ 5,000$ \\
Maximum & $\$ 10,000,000$ & $\$ 100,000,000$ & $\$ 12,000,000$ \\
Standard & $\$ 1,868,411$ & $\$ 14,029,821$ & $\$ 2,856,390$ \\
Deviation & $\mathrm{n}=56$ & $\mathrm{n}=57$ & $\mathrm{n}=56$ \\
Observations & & & \\
\hline
\end{tabular}




\section{Test Case in Forensic Economics: Results Summary}

Thank you for participating in this test case in forensic economics. As you remember, you were all asked to consider the following hypothetical case: "Suppose you have been asked to serve on a jury on a matter dealing with personal injury. In the case before you, a 50-year old construction worker was injured on the job due to the negligence of his employer. As a result, this man had his right leg amputated at the knee. Due to this disability, he cannot return to the construction trade and has few other skills with which he could pursue alternative employment. The negligence of the employer has been firmly established and health insurance covered all of the related medical expenses. Therefore, your job is to determine how to compensate this worker for the loss of his livelihood and the reduction in his quality of life."

Unbeknownst to each of you, you were asked different questions following this introduction.

One-third of you were first asked, "Should the plaintiff in this case be compensated more or less than $\$ 10,000$ ?” and then asked, "How much more or less than $\$ 10,000$ should the plaintiff be compensated?"

The next group were first asked, "Should the plaintiff in this case be compensated more or less than $\$ 10,000,000$ ?" and then asked, "How much more or less than $\$ 10,000,000$ should the plaintiff be compensated?"

The third group was simply asked, "How much should the plaintiff be compensated?”

If you all are rational, as we economists generally assume, your damage awards should have been the same for each group. The actual summary statistics are provided below in Table 1 .

TABLE 1: Results of Starting Point Bias Experiment

\begin{tabular}{lccc}
\hline & $\mathbf{\$ 1 0 , 0 0 0}$ suggested & $\mathbf{\$ 1 0 , 0 0 0 , 0 0 0}$ suggested & No suggestion made \\
\hline Mean & $\$ 803,536$ & $\$ 7,206,040$ & $\$ 2,239,036$ \\
Median & $\$ 375,000$ & $\$ 4,000,000$ & $\$ 1,000,000$ \\
Minimum & $\$ 8,000$ & $\$ 500,000$ & $\$ 5,000$ \\
Maximum & $\$ 10,000,000$ & $\$ 100,000,000$ & $\$ 12,000,000$ \\
Standard & $\$ 1,868,411$ & $\$ 14,029,821$ & $\$ 2,856,390$ \\
Deviation & $\mathrm{n}=56$ & $\mathrm{n}=57$ & $\mathrm{n}=56$ \\
Observations & &
\end{tabular}

A hypothesis test that the mean of the $\$ 10,000$ and $\$ 10,000,000$ group are the same can be rejected at the 99.9\% significance level.

None of the demographic variables revealed significant differences in compensation although males and those identifying themselves as having "Strong Democratic" leanings gave a slightly higher compensation premium (roughly 10\%) in comparison to their counterparts. 


\section{$\underline{\text { Test Case in Forensic Economics }}$}

You are being asked to participate in a research experiment regarding jury awards in lawsuits. Please read the description of the case below and answer the questions that follow. It is critical that you not discuss your answers with any fellow students nor should you look at their survey form until after you have completed the questions and turned in your sheet. The results of the experiment will be made available to you via the Internet within the next several weeks. Thank you for participating in this project.

Suppose you have been asked to serve on a jury on a matter dealing with personal injury. In the case before you, a 50-year old construction worker was injured on the job due to the negligence of his employer. As a result, this man had his right leg amputated at the knee. Due to this disability, he cannot return to the construction trade and has few other skills with which he could pursue alternative employment.

The negligence of the employer has been firmly established and health insurance covered all of the related medical expenses. Therefore, your job is to determine how to compensate this worker for the loss of his livelihood and the reduction in his quality of life.

Should the plaintiff in this case be compensated more or less than $\$ 10,000$ ?

How much more or less than $\$ 10,000$ should the plaintiff be compensated? (Write down the total dollar amount you think the plaintiff should receive.)

What is your gender?

What is your year in school?

Counting a high school AP economics course as 1 semester and not counting any classes you are taking this semester, how many economics courses have you had?
Male $\quad$ Female

First-year Sophomore Junior Senior

0 sem. 1 sem. 2 sem. 3 sem. 4 sem. More

(Circle one. If more than 4 sems., write number.)

What is your hometown? (Write down your city and state/province if you are from U.S. or Canada and your city and country if you are an international student.)

What best describes your political leanings? Strong Democrat
Leaning Democrat
Leaning Strong Republican 


\section{Test Case in Forensic Economics}

You are being asked to participate in a research experiment regarding jury awards in lawsuits. Please read the description of the case below and answer the questions that follow. It is critical that you not discuss your answers with any fellow students nor should you look at their survey form until after you have completed the questions and turned in your sheet. The results of the experiment will be made available to you via the Internet within the next several weeks. Thank you for participating in this project.

Suppose you have been asked to serve on a jury on a matter dealing with personal injury. In the case before you, a 50-year old construction worker was injured on the job due to the negligence of his employer. As a result, this man had his right leg amputated at the knee. Due to this disability, he cannot return to the construction trade and has few other skills with which he could pursue alternative employment.

The negligence of the employer has been firmly established and health insurance covered all of the related medical expenses. Therefore, your job is to determine how to compensate this worker for the loss of his livelihood and the reduction in his quality of life.

Should the plaintiff in this case be compensated more or less than $\$ 10,000,000$ ?

How much more or less than $\$ 10,000,000$ should the plaintiff be compensated? (Write down the total dollar amount you think the plaintiff should receive.)

What is your gender?

What is your year in school?
Male

First-year
Female

Sophomore Junior

Senior

Counting a high school AP economics course as 1 semester and not counting any classes you are taking this semester, how many economics courses have you had?

0 sem. 1 sem. 2 sem. 3 sem. 4 sem. More

(Circle one. If more than 4 sems., write number.)

What is your hometown? (Write down your city and state/province if you are from U.S. or Canada and your city and country if you are an international student.)

What best describes your political leanings? Strong Democrat

Leaning Democrat
Leaning Republican
Strong Republican 


\section{Test Case in Forensic Economics}

You are being asked to participate in a research experiment regarding jury awards in lawsuits. Please read the description of the case below and answer the questions that follow. It is critical that you not discuss your answers with any fellow students nor should you look at their survey form until after you have completed the questions and turned in your sheet. The results of the experiment will be made available to you via the Internet within the next several weeks. Thank you for participating in this project.

Suppose you have been asked to serve on a jury on a matter dealing with personal injury. In the case before you, a 50-year old construction worker was injured on the job due to the negligence of his employer. As a result, this man had his right leg amputated at the knee. Due to this disability, he cannot return to the construction trade and has few other skills with which he could pursue alternative employment.

The negligence of the employer has been firmly established and health insurance covered all of the related medical expenses. Therefore, your job is to determine how to compensate this worker for the loss of his livelihood and the reduction in his quality of life.

How much should the plaintiff in this case be compensated? (Write down the total dollar amount you think the plaintiff should receive.)

What is your gender?

What is your year in school?

\begin{abstract}
Male
\end{abstract}
First-year

Senior

Counting a high school AP economics course as 1 semester and not counting any classes you are taking this semester, how many economics courses have you had?

0 sem. 1 sem. 2 sem. 3 sem. 4 sem. More (Circle one. If more than 4 sems., write number.)

What is your hometown? (Write down your city and state/province if you are from U.S. or Canada and your city and country if you are an international student.)

What best describes your political leanings? Strong Democrat
Leaning Democrat
Leaning Republican
Strong Republican 